\title{
EL DESTINO DE LA SINAGOGA ZAMORANA DE BENAVENTE
}

Cuando el 31 de marzo de 1492 se hizo público el real decreto en virtud del cual los judíos habitantes en los reinos de Castilla y León hubieron de optar por la elección de dos posibilidades extremas -exilio de su secular tierra o conversión al cristianismo-los múltiples y nuevos problemas que se presentaron en las aljamas y juderías castellano-aragonesas adquirieron especiales dimensiones ante la drástica decisión, que en no pocas ocasiones iba acompañada de la auténtica sopresa que produjo en las comunidades judías. Y si variadas y complejas fueron las decisiones que se adoptaron -en ocasiones bajo el móvil de la improvisación - por diversos estamentos cristianos y judíos, el destino de las abandonadas sinagogas y centros anejos sociorreligiosos anduvo por senderos no siempre definidos. Las noticias que nos facilita la dispersa documentación de aquella época es irregular y a veces contradictoria.

Escasa es, en efecto, la información documental que los archivos vienen ofreciendo acerca de los judíos establecidos en la zamorana villa de Benavente, que en época medieval pertenecía a la demarcación territorial de los antiguos obispados de León y Astorga. Y aunque ahora no pretendo iniciar un bosquejo de su historia, sí conviene recordar que, al menos desde 1285 , se la designa como aljama -y no judería- en documentación de carácter económico ${ }^{1}$; por otra parte, no se cita en el repartimiento estipulado cinco años después en 'Huate; en 1430 se declara exento de impuestos a Yudá Comineto, vecino de esa villa². Pero su aljama sí consta pechando en

1 Véase F. BAER, Die Juden im christlichen Spanien [JchS], Berlín 1939, t. 2, p. 72 doc.87; en la siguiente página se menciona al arrendador don Mosé aben Açara, posible vecino de esa villa. En el Archivo Municipal de Benavente se conserva un privilegio de Fernando 1v, de 1295 (era de 1333), en el que se indica que los judíos no compartan con los demás vecinos la administración de las rentas públicas (véase $\mathrm{J}$. LEDO DEl POZO, Historia de la nobilisima villa de Benavente, Zamora 1853; reimpr. Salamanca 1910 , p. 123).

2 Archivo General de Simancas, [AGS], Mercedes, leg. 1, fol. 712, doc. del 28 de octubre. Años antes la comunidad judía de Benavente figura entre las que sufrieron graves persecuciones en los disturbios de 1391, según las qinot que posteriormente 
los repartos generales desde el año 1464 hasta 1491, un año antes de la publicación del edicto de expulsión, a veces con las juderías leonesas de Alijar y Castrocalbón y zamorana de Villafáfila ${ }^{3}$. Se conserva, en fin, un interesante pleito civil iniciado en 1489 por la judía Orovida, mujer que fue de Yucé Amigo, recaudador de Benaventet.

El profesor Francisco Cantera Burgos reunió hace un cuarto de siglo muy abundante información sobre las sinagogas medievales de España en una excelente obra dedicada a tan debatido temas; en esas brillantes páginas no figura, sin embargo, referencia alguna a la sinagoga de la comunidad de Benavente. Ahora puedo ofrecer un nuevo e inédito documento, datado en Benavente el 10 de marzo de 15056; por el que se legaliza la venta de un huerto con sus corrales y otras propiedades ajenas "do solía estar e eslava la signoga de los judíos", otorgada en don Alonso de Pimentel, conde de Benavente. El texto, resumido, dice así:

Sepan quantos esta carta de vençión vieren cómo yo, el bachiller Christóual le Çamora, botycario, vezino desta villa de Benauente, otorgo e conosco por el tenor de la presente que vendo a vos, el ylustre et muy magnífico señor don Alonso Pemintel [sic], conde Benauente, mi señor, vn palomar e huerto con sus corrales e poço e algibe que yo he e tengo e me pertenesçe en esta. . . villa, do solía estar e estava la signoga de los judíos desta. . villa, que ha por linderos de la vna parte çerca desta. . . villa e de las otras partes calles públicas de concejo. El qual ... palomar e huerto, con los ... corrales e poço e algibe ... vos vendo por precio e quantía de veynte mill mrs. de la moneda corriente, que seys coronados hasen el maravedí. .. por quanto los recibí de Diego de Paredes, mercadero, vezino desta. . . villa, en nonbre de vuestra señoría, en buena moneda de oro e plata. . ., en presençia del notario e testigos desta carta.. . Testigos que fueron presentes e vieron firmar su nonbre en el registro desta carta al dicho bachiller e a ella fueron llamados e rogados: el. . liçençiado Alonso de Mercado, alcalde, e Diego de Benauente, secretario de su señoría, e el bachiller Luys

se compusieron para recordar los asaltos a las juderías y aljamas españolas, cuyas consecuencias no acabarían con la comunidad de esa villa: el I marzo 1398 don Maul aben Ahyyón [sic], vecino de Benavente, da por libre a un cristiano de todas las deudas que le debe (Archivo Histórico Nacional [AHN], Osuna, leg. 415/1, núm. 4/2).

3 Véase M. A. LADero Quesidd, "Las juderías de Castilla según algunos «servicios» fiscales del siglo XI", Sef, 31, 1971, 261 (años 1464, 1472 y 1479); F. CiNTERA Bi rgos, “Los repartimientos de Rabí Jaco aben Nuñez”, ibid., 236 (años 1472 y 1474); AGS, Registro General del Sello, fol. 257, de 29 de enero 1488; fol. 212 , a 20 de enero 1489 , y fol. 54 , a 10 marzo 1491 .

4 Espero dar pronto a conocer el documento, custodiado en el Archivo de la Chancillería de Valladolid, (Cf. F. Baer, JchS., t. 2, p. 428, doc. 388 ).

s Sinagogas españolas, Madrid 1955.

- Original, en papel, en AHN, Osuna, leg. 420/1, núm. 2/ 7 (olim: caxón 2, leg. 3, núm. 44). 
Alonso e Christóual Garçía, contador de su señoría, vezinos. . . de Benauente. . [firmado y rubricado:] Acaçio de Caruajal, notario.

$\mathrm{Su}$ lectura permite algunas reflexiones:

1) existencia documental de, al menos, una sinagoga en Benavente durante los últimos años de permanencia oficial de los judíos en aquella villa;

2) su estructura material no sería de destacado valor arquitectónico cuando, poco después de 1492, ya demolida, ni siquiera se conservaban los cimientos;

3) la aljama, acaso desde el ordenamiento sobre moros y judíos firmado en 1412 por la reina doña Catalina, estaba separada de la población cristiana mediante el habitual sistema de cercas;

4) el, según parece, primer propietario de la ex-sinagoga, el boticario Cristóbal de Zamora, obteñdría su posesión por reducida cantidad de dinero - dado el hipotético escaso valor del edificio-o, lo que es más probable, por concesión real, según costumbre ampliamente documentada en similares ocasiones;

5) Cristóbal de Zamora ¿era judeoconverso? Cualquier afirmación, incluso contemplando las sugerencias que pueden facilitar su oficio y apellido, pertenece al ámbito de la conjetura, y

6) el precio de adquisición - $200000 \mathrm{mrs}$. - era, a principios del siglo XVI, relativamente modesto para valorar un terreno cultivable en el nivel doméstico.

La deseable identificación del edificio y de los motivos que impulsaron la demolición de la sinagoga de Benavente sólo permaneció en el recuerdo de quienes, además de otras múltiples añoranzas, prefirieron el destierro camino de Portugal. Los judeoconversos que, por muy particulares razones, se acercaron a la pila bautismal intentarían rememorar en amargo silencio el imprevisto destino de su antiguo centro de oración comunitaria.

Carlos Carrete Parrondo

Universidad Pontificia de Salamanca. 